Bartosz Janik

\title{
Kilka słów o teorii pozycji normatywnych
}

\section{Wprowadzenie}

Prezentowana w tym opracowaniu teoria pozycji normatywnych ma posłużyć do ilustracji tezy, że formalizacja pojęć związanych z językiem prawnym nie tylko pozwala na precyzyjne ich wyrażenie, lecz także może posłużyć jako narzędzie wskazujące na możliwe problemy związane z ich użyciem. Centralne we wspomnianej teorii jest pojęcie obowiązku, które spełni rolę najważniejszego z fundamentalnych pojęć prawnych, o których pisał W. N. Hohfeld ${ }^{1}$. Posłuży ono jako pojęcie formalnie pierwotne, za pomocą którego zdefiniujemy inne pojęcia. W tym tekście nie będę się zajmował problematyką uprawnień (rights), aczkolwiek szkicując teorię, pokażę, w jaki sposób mogą one zostać w naturalny sposób dołączone do systemu. Nie posiadamy jednak adekwatnej formalnej teorii zarówno dotyczącej charakterystyki uprawnień, jak i zawierającej ogólną charakterystykę uprawnień i obowiązków. Dodatkowo pewne prace zostały podjęte $\mathrm{w}$ celu uzupełnienia tego systemu o formalną reprezentację normatywnej siły prawa, której to reprezentacji brak w oryginalnym sformułowaniu teorii pozycji normatywnych, a także o dodanie pewnych struktur formalizujących posiadanie przez agenta określonych informacji ${ }^{2}$.

1 W. N. Hohfeld, Some fundamental legal conceptions as applied in judicial reasoning, „Yale Law Journal” 1913, no. 23.

2 Pojęcie normatywnej/zinstytucjonalizowanej siły systemu prawnego zostało sformalizowane w: A. J. Jones, M. Sergot, A formal characterisation of institutionalised power, „Logic Journal of the IGPL" 1996, no. 4(3), zaś perspektywa związana z posiadaniem przez agenta określonych informacji została rozwinięta w A. Jones, X. Parent, Normative-informational positions: a modal-logical approach, „Artificial Intelligence and Law” 2008, no. 16 (1) oraz A. J. Jones, On normative-informational positions, [w:] A. Lomuscio, D. Nute (eds), Deontic Logic in Computer Science. Proceedings of the 7th Int Workshop on Deontic Logic in Computer Science, DEON 2004, Berlin 2004. 


\section{Zarys teorii ${ }^{3}$}

2.1. W ujęciu M. Sergota problemy, z którymi musi się zmierzyć formalny model interakcji wielu podmiotów $\mathrm{z}$ systemem prawnym, prezentują się następująco ${ }^{4}$ :

1) formalne zdefiniowanie sposobów interakcji pomiędzy agentami i sytuacji, w których obowiązuje jedynie ought-to-be, tj. kiedy wyznaczony został tylko stan świata pożądany przez definiującego obowiązki ${ }^{5}$;

2) rozwiązanie problemów z używaniem wyrażeń STIT-podobnych - ogólna teoria musi pokazywać, $\mathrm{w}$ jaki sposób wyrażenia postaci ,agent $x$ brings-itabout-that F" mogą być wzajemnie łączone i jakie warunki powinny być nakładane na ich kombinacje;

3) potrzeba zdefiniowania abstrakcyjnego pojęcia pozycji (lub/oraz sytuacji) prawnej, niezależnego od użytej logiki;

4) problem $z$ ujęciem normatywności oraz wynikających $z$ niej uprawnień i obowiązków oraz problem zajmowania przez niektórych agentów pozycji prawnie uprzywilejowanej;

5) precyzyjne zbadanie właściwości metalogicznych systemu i odniesienie ich do możliwych interpretacji zdefiniowanych pozycji/sytuacji.

Przyjmując pojęcie obowiązku jako pierwotne, można definiować pojęcie uprawnienia $\mathrm{w}$ następujący sposób: jeżeli agent $x$ ma uprawnienie względem agenta $y$, takie, że $F$ (powinno zostać wykonane przez $y$ ), to jednocześnie agent $y$ ma obowiązek wobec agenta $x$ dokonania tej czynności formalnie:

$$
U(x, y, F) \leftrightarrow O(y, x, F)
$$

W podobny sposób można zdefiniować pojęcie wolności (wolność do zrobienia $F$ to brak obowiązku zrobienia nie- $F$ ). Problem pojawia się w sytuacji, gdy budujemy spójny system formalny dla wszystkich pojęć i okazuje się, że wiele z metalogicznych właściwości systemu pociąga za sobą nieintuicyjne z punktu widzenia prawa wnioski. Dlatego też prezentowana teoria obejmuje zakresem tylko pojęcie obowiązku prawnego.

3 Ograniczam się do podania podstawowych elementów teorii wraz z krótkim komentarzem. Algebraiczne wprowadzenie do systemu jest zbędne, gdyż jasno zostało przedstawione w pracy Sergota. Z drugiej strony, celem niniejszego opracowania jest raczej zwrócenie uwagi na pewne problemy relewantne z punktu widzenia aplikacji systemów AI w prawie niż kompleksowe omówienie metalogicznych własności tego systemu.

${ }_{4}$ M. Sergot, A computational theory of normative positions, „ACM Transactions on Computational Logic" 2001, vol. 2, no. 4 (October), s. 583 oraz A. J. Jones, M. Sergot, op. cit.

5 Na temat odróżnienia ought-to-be oraz ought-to-do por. J. Horty, Agency and Deontic Logic, Oxford 2009. Znaczenie tego odróżnienia jest marginalne z punktu widzenia systemu Sergota. 
2.2. Standardowa logika deontyczna to rachunek nadbudowany nad klasycznym rachunkiem zdań, poprzez dodanie do niego modalnego operatora obowiązku $(O)$ oraz zdefiniowanie dozwolenia jako $P A:=\neg O \neg A$. Dodatkowo, do słownika dodane są reguły dodawania operatora obowiązku oraz jego eliminacji ${ }^{6}$. Standardowa logika deontyczna jest narzędziem niewystarczającym do wyrażenia teorii obowiązku z uwagi na paradoksy, które generuje (contrary-to-duty, paradoks Rossa itp.), dlatego też rozszerzona zostaje przez dodanie perspektywy „agentowej” oraz narzędzi do reprezentowania działania agenta. Jako remedium na trudności wynikające ze wskazanych wyżej problemów oraz ograniczeń logiki deontycznej, w pracach Sergota jako adekwatny model formalny wykorzystywane jest zmodyfikowane podejście deontyczne. Jego korzeni można szukać w formalnych teoriach S. Kangera i L. Lindahla, w którym przyjmuje się standardową logikę deontyczną oraz wyrażenie?:

$$
E_{x} A
$$

znaczące: ,agent $x$ sees to it that $\backslash$ bring it about that $A$ " agentów $X$, oraz $A$ należy do zbioru możliwych akcji, oraz schemat:

$$
A \leftrightarrow B \rightarrow E_{x} A \leftrightarrow E_{x} B
$$

i tezę

$$
E_{x} A \rightarrow A
$$

która oznacza udane działanie agenta, tj. założenie, że jeżeli „x sees to it that $A$ ", to akcja ta zostaje urzeczywistniona. Zagadnieniem wypadkowym, które nie jest potrzebne $\mathrm{w}$ toku konstrukcji formalnego systemu wykorzystywanego do implementacji w ramach AI, jest problem interpretacji semantyki budowanej w taki sposób. Wydaje się, że jej możliwoświatowa interpretacja będzie w stanie wnieść wiele ciekawych treści do dyskusji dotyczącej natury i funkcji obowiązku prawnego.

${ }^{6}$ Przegląd logik deontycznych Czytelnik znajdzie w: L. Aqvist, Deontic logic, [w:] D. M. Gabbay, F. Guenthner (eds), Handbook of Philosophical Logic, vol. 8, London 2002 oraz w: P. McNamara, Deontic logic, [w:] D. M. Gabbay, J. Woods (eds), Handbook of the History of Logic, vol. 7: Logic and the Modalities in the Twentieth Century, Amsterdam 2006.

7 Warto nadmienić, że wyrażenie to nie stanowi istotnego novum ani w logice filozoficznej, ani w filozoficznej analizie pojęcia akcji. Operator został wprowadzony i analizowany m.in. w: N. Belnap, M. Perloff, M. Xu, Facing the Future. Agents and Choices in Our Indeterminist World, Oxford 2001 oraz J. Horty, op. cit. Istotną cechą podejścia Sergota jest wykorzystanie pojęcia logiczno-filozoficznego do konstrukcji formalnego systemu na potrzeby sztucznego systemu podejmowania decyzji.

8 Nie tłumaczę tego wyrażenia; w polskiej literaturze można spotkać tłumaczenie „sprawca $x$ gwarantuje prawdziwość $A$ ”, które wydaje się oddawać intuicję związaną z użyciem tego wyrażenia - por. M. Klinowski, Logiczna problematyka czynu i sprawstwa, Kraków 2011, s. 73. 
2.3. Centralnym punktem teorii Kangera-Lindahla, na której opiera się Sergot, jest pojęcie pozycji normatywnej, które tworzy się przez wyliczenie (tworzenie schematu generującego) oparte na pozytywnych i negatywnych obowiązkach oraz zachowaniach agentów w określonej sytuacji ${ }^{9}$. Możliwe relacje (pozycje) prawne jednego agenta reprezentuje schemat:

$$
\pm O \pm E_{a} \pm F
$$

który może być rozwinięty w sześcioelementowy spójny i złożony z elementów wzajemnie się wykluczających zbiór pozycji normatywnych jednego agenta. Analogiczny schemat dla dwóch agentów:

$$
\pm O \pm\left(\begin{array}{c}
E_{a} \\
E_{b}
\end{array}\right) \pm F
$$

gdzie $a, b$ oznaczają agentów, a $O$ pewien ich obowiązek w związku z sytuacją $F$. Można zatem powiedzieć, że powyższy schemat określał będzie istnienie, lub nie, obowiązku w związku z wyborem jednej z dwóch alternatyw, w związku z dokonaniem, lub nie, określonej akcji. Ten prosty schemat generuje 16 możliwych wyrażeń (np. $O E_{a} F, O E_{b} \neg F$ ). Denotuje on również pewien określony zbiór (analogicznie wygląda to w ramach zbioru dla jednego agenta):

$$
\left\| \pm O \pm\left(\begin{array}{c}
E_{a} \\
E_{b}
\end{array}\right) \pm F\right\|
$$

tak zwanych maksymalnych kombinacji pozycji normatywnych z określonym dla nich schematem wyboru $\Phi$. Formuła $\|\Phi\|$ oznaczała będzie maksymalny spójny zbiór kombinacji wyrażeń należących do $\Phi$. Zbiór jest maksymalną kombinacją, gdy dodanie do niego kolejnej usuwa jego spójność. Maksymalne kombinacje są podziałem zbioru logicznych możliwości. Maksymalne kombinacje $E_{a}$ nazywamy normatywnymi pozycjami jednego agenta. Wraz ze zwiększaniem liczby agentów, zwiększa się nam (kombinatorycznie) zbiór maksymalnych kombinacji, z których usuwane są te, które nie są dopuszczalne przez system aksjomatów dla określonej logiki deontycznej i te, które wyklucza przyjmowanie pewnych pierwotnych założeń (różnie w systemach Kangera, Lindahla i Sergota) ${ }^{10}$.

9 M. Sergot, op. cit., s. 591.

${ }^{10}$ Ibidem, s. 591-592 oraz M. Sergot, F. Richards, On the representation of action and agency in the theory of normative positions, „Fundamenta Informaticae” 2001, no. 45. 
Prosty schemat zaprezentowany powyżej został rozwinięty przez Lindahla, który zmienił sposób reprezentowania maksymalnych kombinacji poprzez dokonanie podziału tego, co zostało przedstawione przez Kangera jako jedna maksymalna kombinacja:

$$
\| \pm O \pm\| \pm\left(\begin{array}{c}
E_{a} \\
E_{b}
\end{array}\right) \pm F\|\|
$$

na iloczyn dwóch niezależnych kombinacji:

$$
\left\| \pm O \pm E_{a} \pm F\right\| \cdot\left\| \pm O \pm E_{b} \pm F\right\|
$$

zwiększając możliwości interpretacji wyrażeń (np. dodając do zbioru możliwych zdań formułę $\neg E_{a} F \wedge \neg E_{a} \neg F$, którą możemy interpretować jako ,pasywność" agenta). Pozycje normatywne u Lindahla tworzą więc partycję zupełną, podczas gdy Kanger dokonuje partycji, ale pozbawionej zupełności ${ }^{11}$. Jones i Sergot dokonali dalszego rozwinięcia systemu Lindahla, jednakże nie zmieniając jego głównych założeń (dopuszczają oni sytuację, w której działanie agenta odbywa się w sytuacji, w której zachodzi stan przeciwny do pożądanego ${ }^{12}$ ). Jones i Sergot zaobserwowali również, że powyższy sposób przedstawiania pozycji różni się od następującego zapisu:

$$
\| \pm O \pm\| \pm E_{a} \pm F\|\| \cdot\| \pm O \pm\| \pm E_{b} \pm F\|\|
$$

Ten zapis dopuszcza wprowadzenie w naturalny sposób operatora powinności jako formuły dualnej do pojęcia obowiązku.

Lindahl pierwsze z podejść (formuła 8) uznał za kolektywistyczne, drugie zaś (formuła 9) za indywidualistyczne. W wypadku indywidualistycznym pozycji normatywnych jest $\left(2^{3}-1\right) \cdot\left(2^{3}-1\right)=49$, z których 35 jest wewnętrznie spójnych. Analogiczne obliczenia dla systemu Kangera dają liczbę 26 możliwości. Podejście kolektywistyczne różni się od podejścia indywidualistycznego, gdyż zachodzi równość ${ }^{13}$ :

$$
\| \pm O \pm\| \pm\left(\begin{array}{c}
E_{a} \\
E_{b}
\end{array}\right) \pm F\|\|=\| \pm O \pm\| \pm E_{a} \pm F\|\cdot\| \pm E_{b} \pm F\|\|
$$

${ }^{11}$ Pojęcie partycji odgrywa w opisywanym systemie bardzo ważną rolę, jednak z uwagi na jego techniczny charakter pozostawiam je bez precyzyjnej definicji. Za pomocą pojęcia rafinacji i partycji zostają wprowadzone do systemu narzędzia formalne, umożliwiające wybór interesujących nas formuł na podstawie założonej logiki oraz pożądanych cech systemu.

${ }^{12}$ M. Sergot, op. cit. oraz A. J. Jones, M. Sergot, op. cit.

${ }^{13}$ Zapis z zastosowaniem obserwacji Jonesa i Sergota umożliwiającej wprowadzanie dozwolenia. 
tzn. formuły podejścia kolektywistycznego implikują formuły podejścia indywidualistycznego; te ostatnie mogą być przedstawione jako kombinacje tych pierwszych. Mówimy, że podejście kolektywistyczne jest rafinacją (refinement) podejścia indywidualistycznego. Uzyskuje się dzięki temu bardziej precyzyjny język za cenę wzrostu złożoności obliczeniowej ${ }^{14}$. Ostatecznie, zbierając elementy rozwinięte przez Jonesa i Sergota, można powiedzieć, że teoria pozycji normatywnych dla jednego agenta reprezentowana będzie przez następujący schemat:

$$
\| \pm O \pm\| E_{a} \pm F\|\cdot\| \pm F \|
$$

Schematy dla wielu agentów budowane będą w sposób kolektywistyczny.

2.4. Na podstawie tych uwag wprowadzających można w sposób skrótowy scharakteryzować sposób działania systemu rozwiniętego przez Jonesa i Sergota. Pierwszym krokiem jest wybór określonej partycji, która wydaje się interesująca z punktu widzenia rozważanego problemu. W partycji tej należy wskazać również pozycje, które będą występowały w rozważanych okolicznościach. W systemach, w których nie jest możliwe, z uwagi na ich złożoność, wskazanie wszystkich takich pozycji, te niewyróżnione będą reprezentowane jako alternatywy lub koniunkcje tych wyróżnionych. Procedura wyłaniania interesujących nas pozycji musi być przeprowadzana etapowo, gdyż na wygenerowanie listy pozycji oraz jej przegląd potrzeba olbrzymich ilości czasu. Na każdym z etapów odrzucane są kolejne zbiory pozycji i dodawane kolejne kryteria ${ }^{15}$. Rezultatem działania jest wybór określonej pozycji normatywnej, odpowiadającej zdefiniowanym okolicznościom. Wybór takiej pozycji umożliwia sformułowanie zaleceń dotyczących obowiązanego działania agenta/agentów i wzajemnych relacji pomiędzy agentami.

\section{Podsumowanie}

Na końcu chciałbym odpowiedzieć na pytanie, jaki wpływ może mieć konstruowanie systemów formalnych reprezentujących rzeczywistość prawną na tę rzeczywistość. Przede wszystkim odniosę się do propozycji M. Sergota i wskażę na jej założenia, które mogą być nieobojętne z punktu widzenia prawa, aby w konkluzji sformułować kilka uwag ogólnych. Chciałbym jednocześnie dodać, że prezentowana lista nie jest zbiorem zarzutów czy też powodów, dla których powinniśmy przywołaną teorię odrzucić czy uznać ją za złą. Lista jest raczej wyliczeniem elementów, które powinny zostać dodatkowo opracowane teoretycznie lub dodane do systemu próbującego sformalizować rozumowania o normach i z norm.

\footnotetext{
${ }^{14}$ M. Sergot, op. cit.

${ }^{15}$ Cała procedura jest jeszcze bardziej skomplikowana. Po szczegóły odsyłam do sekcji 7 oryginalnego artykułu - M. Sergot, op. cit.
} 
Techniczne kwestie otwarte są następujące.

1. Należy zadać pytanie: w jaki sposób ogranicza nas wybór określonego rachunku logicznego? (w tym przypadku wyborem był SDL, ale możemy go dowolnie modyfikować). Kwestia ta jest bardzo istotna $\mathrm{w}$ aspekcie wspomnianych wcześniej paradoksów logicznych związanych z wnioskowaniem o normach lub na podstawie norm (np. w jaki sposób reprezentować można obowiązki warunkowe oraz w jaki sposób ominąc problem contrary-to-duty). Co do rozstrzygnięcia problemu możliwości wyboru logiki leżącej u podstaw całego systemu prawnego nie ma zgody, jednakże kwestia ta musi zostać w jakiś sposób włączona i rozwiązana na gruncie implementacji opisywanego systemu.

2. Czy założona ontologia pozycji/sytuacji prawnej (jako pewien wariant ontologii sytuacji) nie jest zbyt prosta? Ontologia sytuacji może być budowana jako teoria drugiego, a nawet wyższego rzędu z uwagi na konieczność kwantyfikacji po predykatach ${ }^{16}$. W tym wypadku pojęcie sytuacji normatywnej jest pojęciem pierwotnym. Wskazuję na pewne filozoficzne problemy związane z budową systemów formalnych. Pewne pojęcia zostały przyjęte bezrefleksyjnie, podczas gdy toczy się debata filozoficzna oraz teoretycznoprawna dotycząca ich statusu.

3. Wydaje się również, co zostało podniesione we wprowadzeniu, iż rachunek jest zbyt ubogi, aby formalizować w pełni możliwe sytuacje normatywne (brak możliwości wycofywania się, zaniechania działań czy wnioskowania $\mathrm{w}$ ramach sprzecznych postaw agentów). Problem sprawstwa i zaniechania $\mathrm{w}$ kontekście prawnym był formalizowany w literaturze, ale w bardziej filozoficzny sposób ${ }^{17}$.

4. Dodatkowe problemy obejmują takie zagadnienia, jak: problem schematu faktualnego (tj. sytuacji, kiedy zachodzą pewne warunki faktyczne i w rezultacie tego tworzy się pozycja normatywna), jak formalizować takie sytuacje (w ramach tego wyboru: jak określić klasę sytuacji skorelowaną z zajściem określonego stanu faktycznego? ${ }^{18}$ ), a dodatkowo, czy niezbędne jest wprowadzenie elementu czasowości do naszych rozumowań o obowiązkach? (wiązałoby się to z wprowadzeniem operatorów temporalnych do logiki leżącej u podstaw teorii).

Na podstawie informacji dotyczących teorii pozycji normatywnych można podjąć zagadnienie dwustronnego warunkowania pomiędzy rzeczywistością prawną a systemem formalnym. Główną osią dyskusji w tym przedmiocie jest pytanie: czy takie warunkowanie może być symetryczne, czy też z konieczności przyjmowania określonych założeń teoretycznoprawnych

\footnotetext{
${ }^{16}$ A. Biłat (red.), Aporie ontologii sytuacji, Lublin 2009.

${ }^{17} \mathrm{M}$. Klinowski, op. cit.

${ }^{18}$ M. Sergot, op. cit., s. 590.
} 
(doktrynalnych) powinno być przeciwsymetryczne? W najprostszym przypadku możemy powiedzieć, że rzeczywistość prawna umożliwia tworzenie jej formalnych modeli i nie zachodzi pomiędzy nimi zwrotne warunkowanie. Czy jest tak na pewno? Wydaje się, że tworzenie określonych systemów formalnych, poprzez zastosowanie ściśle logicznej aparatury do prezentacji problemów prawnych, samo z siebie może wpływać (na drodze interpretacji) na postrzeganie tych problemów. Głównie w tym elemencie dostrzegam możliwość współpracy na linii: teoria prawa - nauki kognitywne. 